\title{
De Finetti on the Insurance of Risks and Uncertainties
}

\author{
Alberto Feduzi, Jochen Runde, and Carlo Zappia
}

\begin{abstract}
In the insurance literature it is often argued that private markets can provide insurance against 'risks' but not against 'uncertainties' in the sense of Knight ([1921]) or Keynes ([1921]). This claim is at odds with the standard economic model of risk exchange which, in assuming that decision-makers are always guided by precise point-valued subjective probabilities, predicts that all uncertainties can, in theory, be insured. Supporters of the standard model argue that the insuring of highly idiosyncratic risks by Lloyd's of London proves that this is so even in practice. The purpose of this paper is to show that Bruno de Finetti, famous as one of the three founding fathers of the subjective approach to probability assumed by the standard model, actually made a theoretical case for uncertainty within the subjectivist approach. We draw on empirical evidence from the practice of underwriters to show how this case may help explain the reluctance of insurers to cover highly uncertain contingencies.
\end{abstract}

1 Introduction

2 Knight and Keynes on the philosophy of unknown probabilities and Lloyd's of London

\section{$2.1 \quad$ Knight \\ 2.2 Keynes}

$3 \quad$ Insuring unique events: the subjectivist viewpoint as represented by de Finetti

$4 \quad$ The 'philosophy' of practitioners

5 De Finetti on uncertainty in Knight and Keynes and on insurability

5.1 De Finetti on Knight

5.2 De Finetti on Keynes

6 Empirical evidence on insurance under ambiguity

7 Conclusion 


\section{Introduction}

In a recent article, Kyburg ([2002], p. 15) observes that insurance provides 'the simplest and clearest use of probability as a guide in life' and discusses the meaning of probability with respect to the possibility of providing coverage against unique events. He observes that there are insurance companies who issue policies on blatantly 'unique' objects or events, and indeed Lloyd's of London is famous for its willingness to insure almost anything for the right premium. Kyburg concludes that since 'from the point of view of the insurance company, every insurance contract is a single case, which is either won or lost ... it is curious ... that very little of the philosophical literature discusses insurance' (Kyburg [2002], p. 15).

Authors interested in the philosophical foundations of probability and its application to economic theory have however devoted considerable attention to the possibility of applying probabilistic reasoning to the insuring of single cases. The preconditions for the insurability of a specific event are central to Knight's ([1921]) distinction between risk and uncertainty, where uncertainty is specifically defined as a risk that is not insurable. Keynes ([1921]) tackles the same issue in his Treatise on Probability when distinguishing cases in which degrees of belief can be represented as numerically definite probabilities and cases in which they cannot.

While the distinction between risk and uncertainty has wide currency, however, it tends to be rejected by economists accustomed to the Subjective Expected Utility (SEU) model associated with Savage ([1954]), which incorporates the 'orthodox' subjective conception of probability widely regarded as stemming from the work of Bruno de Finetti ([1937]) along with Frank Ramsey ([1926]) and Savage himself. In terms of the SEU model, the probability of a proposition or event measures the strength of the decisionmaker's degree of belief in that proposition or event, and it is assumed that the decisionmaker always behaves 'as if' she assigned numerical probabilities to the events impinging on her actions, and calculates the value of any risky option as the sum of the probability-weighted utility of its possible consequences. The rationale for adopting the SEU model to analyse the insurance market is straightforward: since the insurer can attach sharp numerical probabilities to every event and thus make the insurance mechanism work, the standard economic model of risk exchange (the so-called Arrow- 
Borch model) predicts that all the individual uncertainties will be insured, and that competition in the insurance market will lead to a Pareto-efficient allocation of risk (Gollier [2005], [2007]).

The trouble with this view is that the predictions of the economic model of risk exchange are clearly contradicted even by casual observation. To be sure, some idiosyncratic risks associated with specific events may find insurance cover as in the practice of Lloyd's of London (Borch [1976]). But insurance markets still fail to insure risks such as terrorist attacks, large environmental catastrophes, the transmission of new diseases, genetic manipulation and so on. And even though the economics literature has provided various explanations of these failures (e.g. asymmetric information, transaction costs and problems of liability), the reports of insurance firms and financial consultants often address this issue in terms of 'unknown probabilities'. That is to say, it is argued in these reports that whenever it is not possible to attach sharp numerical probabilities to certain contingencies, the insurer is not able to calculate an appropriate premium and make the actuarial mechanism work (Swiss Re [2005]; Taylor and Shipley [unpublished]). As the issues involved here concern the theoretical foundations of unknown or absent probabilities, the philosophy of probability is a good place to start (Kyburg [2002]). Indeed, outside a strictly subjectivist interpretation of probability it is taken for granted that different philosophical theories of probability may suggest different decision theoretic approaches (Walley [1991]; Billot [1992]) and contribute to an explanation of the limits to insurability in the private markets (Jeleva and Villeneuve [2004]). However, it has remained unnoticed that de Finetti himself dealt with this issue in generally overlooked parts of his work. Our purpose is thus to highlight and examine de Finetti's theoretical case for a distinction between risk and uncertainty within the subjectivist approach, and his arguments to the effect that even the use of subjective probabilities does not always guarantee the completeness of insurance markets.

We start with the theories of probability and uncertainty advanced by Knight and Keynes, and go on to discuss the consequences of their approaches for the practice of the insurance markets. It turns out that although their two theories are usually classified as opposites, it is legitimate to speak about Knightian and Keynesian uncertainty in the same breath and that both authors provide an explanation of the failure of the insurance market 
to insure truly 'uncertain' events. We then consider how de Finetti's work is usually invoked to explain why the Knight/Keynes distinction between risk and uncertainty is theoretically meaningless and practically irrelevant to the analysis of the functioning of the insurance market. It turns out that the received view of de Finetti, which is at odds with the practice of most underwriters confronting idiosyncratic risks, does not exhaustively represent his own position on the subject. We show this by analysing two overlooked excerpts from de Finetti's vast contribution to economics and statistics, published in Italian. The first, which appeared in the 1967 Economia delle Assicurazioni and has never been translated into English, comments on Knight's distinction between risk and uncertainty. The second, taken from a 1938 review article on the logical approach to probability translated into English only as late as 1985, offers de Finetti's early thoughts on Keynes's notion of non-numerical probability, a theme later assessed, still only in Italian by de Finetti and Savage ([1962]).

It is our contention that these excerpts show an attitude towards the issue of uncertainty and its justification in the theory of probability that does not conform to the traditional interpretation of de Finetti as the champion of a strictly subjective approach. In particular, we argue that de Finetti's discussion of the key elements underpinning Knight's and Keynes's analyses of uncertainty makes a theoretical case for uncertainty within the subjectivist approach and provides solid theoretical ground for understanding the failure of insurance market to cover highly uncertain events. We conclude with some empirical evidence on the reluctance of insurers to cover highly uncertain contingencies (Hogarth and Kunreuther [1985], [1989], [1995]; Kunreuther et al. [1995]; Cabantous [2007]) and some practical implications of our interpretation of de Finetti.

\section{Knight and Keynes on the philosophy of unknown probabilities and Lloyd's of London}

Knight ([1921]) and Keynes ([1921]) are often cited in discussions of the risk/uncertainty distinction and the limits of insurability. While their philosophical approaches are in many respects quite different, they display remarkably similar views about when it is 
possible to determine numerically definite probabilities and when it is not. Moreover, both authors appeal to the practice of Lloyd's of London to illustrate their views.

\subsection{Knight}

Frank Knight's ([1921]) seminal Risk, Uncertainty and Profit is famous as the source of the distinction between risk and uncertainty. This distinction is based on an analysis of 'probability situations'. Situations of 'risk' are ones in which it is possible to determine numerically definite probabilities, usually statistical frequencies, situations of 'uncertainty' ones in which it is not possible to do so. ${ }^{1}$

Since statistical probabilities are generally seen as a property of the external world, Knight's distinction seems to presuppose an objective interpretation of probability. With respect to situations of uncertainty, Knight observes: 'The liability of opinion or estimate to error must be radically distinguished from probability ... for there is no possibility of forming in any way groups of instances of sufficient homogeneity to make possible a quantitative determination of true probability' (Knight [1921], p. 231). While estimates are identified as a 'third type of probability judgment', he does not make them the subject of a systematic treatment as probability judgements per se.

Knight's commitment to the objective, statistical interpretation of probability seems to inform his view that private insurance markets generally fail to cover 'uncertain' contingencies. According to Knight, only 'an uncertainty which can by any method be reduced to an objective, quantitatively determinate probability, can be reduced to complete certainty by grouping cases' (Knight [1921], pp. 231-2). Insurance activity is then 'an illustration of the principle of eliminating uncertainty by dealing with groups of

\footnotetext{
${ }^{1}$ Knight's complete taxonomy of probability situations includes three different types: 1 ) classical or a priori probability, i.e. the ideal case in which numerical probabilities can be computed on general principles, namely where they are assigned to an exhaustive list of equiprobable and mutually exclusive possible events; 2) statistical probability, i.e. situations in which frequencies may be derived on the basis of an empirical classification of outcomes obtained in classes of more or less homogeneous trials; 3) estimates, i.e. situations in which it is not possible to calculate a priori probabilities or where there are insufficient trials 'like' enough to form a reference class of even more or less homogeneous trials on the basis of which frequencies can be determined (Runde [1998]). Knightian risk is associated with 1) and 2), Knightian uncertainty with 3).
} 
cases instead of individual cases' (Knight [1921], p. 245), and the application of the insurance principle by which a larger contingent loss is converted into a smaller fixed charge strictly depends on the 'measurement of probability on the basis of a fairly accurate grouping into classes' (Knight [1921], p. 246). ${ }^{2}$ It is impossible to provide insurance in situations of uncertainty, on this view, since the events to be insured against 'are far too unique, generally speaking, for any sort of statistical tabulation to have any value for guidance'. In fact most business decisions, according to Knight ([1921], p. 231), are ones in which the idea of an objectively measurable probability or chance simply don't apply.

On this perspective, life insurance is the branch of insurance in which contingencies are most accurately measurable and amenable to 'mathematical' treatment, while in cases such as insurance against sickness and accident an objective classification of cases is deemed to be impossible because of the practical difficulties in the measurement of 'real probability' in a particular case (Knight [1921], p. 246). Knight does not deny that insurance is sometimes offered under these circumstances, but argues that 'it is notorious that such policies cost much more that they should' and 'insurance does not take care of the whole risk' (Knight [1921], pp. 248-9). Nonetheless he seems to be puzzled by the 'unusual forms of policies issued by some of the Lloyd's underwriters' when insuring the loss of ships at sea or the destruction of crops by storm. In extreme cases such as the insurance offered to a business for whatever reason 'concerned that a royal coronation will take place as scheduled', Knight ([1921], p. 250) concludes that 'almost pure guesswork' substitutes for “"scientific” rate-making'.

But as the practice of insuring of unique events does not conform to Knight's requirement of sufficient trials homogeneous enough to form a reference class relative to which an objective probability can be determined, there is no clear equivalence between his theoretical classification and the variety of actual insurance of business hazards. Knight recognizes this difficulty but argues nonetheless that insurance is offered in these cases possibly on the grounds of a 'certain vague grouping of cases on the basis of intuition or judgment' (Knight [1921], p. 250). This tension between theory and practice

\footnotetext{
${ }^{2}$ On this view market insurance mostly amounts to an application of the law of large numbers. On this point see Section 4.
} 
does not seem to worry Knight, who concludes his analysis with a long discussion of institutional aspects of insurance markets such as the conservative attitude of competent insurers and the offsetting of losses and gains through consolidation.

\subsection{Keynes}

In his A Treatise on Probability, Keynes conceives probability as a logical 'probability' relation between a set of evidential propositions and a conclusion. In terms of his notation, if $e$ is a set of evidential premises and $h$ the conclusion of an argument, then $p=$ $h / e$ is the degree of rational belief that the probability relation between $e$ and $h$ justifies. If $h$ follows as a deductive consequence of $e$, then $p=1$. If not- $h$ follows as a deductive consequence of $e$, then $p=0$. In all intermediate cases, where $e$ provides some but not conclusive grounds for believing or disbelieving $h, p$ will lie somewhere in the interval [0,1]. Probabilities are epistemic on Keynes's approach, as they are regarded as a property of how individuals think about the world. They are subjective, moreover, insofar as they are always relative to the available evidence $e$, which may differ from individual to individual. However, given a set of evidential premises $e$ and a conclusion $h$, Keynes maintains that the probability $p=h / e$ is objective and corresponds to the degree of belief it is rational for an individual to hold.

One of the most distinctive features of Keynes's theory from a contemporary perspective is that he rejects the idea that probabilities can always be given a representation by real numbers. ${ }^{3}$ In his view, degrees of belief can be measured numerically only where it is legitimate to apply the 'Principle of Indifference' or where it is possible to estimate statistical frequencies. ${ }^{4}$ Since the preconditions for the application of the principle of indifference or the frequency approach are so rarely met, in many

\footnotetext{
${ }^{3}$ This idea is instead implied by the definition of frequency probability as the ratio of favourable to total number of cases. Subjectivists are committed to it through the Dutch book argument (de Finetti [1937]).

${ }^{4}$ According the Principle of Indifference, if each of an exhaustive and mutually exclusive list of indivisible hypothesis $h_{i}(i=1,2 \ldots n)$ is judged to be equiprobable relative to $e$, then the probability $p\left(h_{i} / e\right)=1 / n$ for each $i$. On the frequency view, the probability of an hypothesis $h$ is $p$ if the relative frequency of $h$ in a large number of repeated trials performed under identical conditions tends to $p$.
} 
cases 'no exercise of the practical judgment is possible, by which a numerical value can actually be given to the probability' (Keynes [1921], p. 29).

Indeed Keynes ([1921], p. 29) goes even further than insisting that many probabilities are non-numerical. In many cases, he argues, pairs of probability relations may not even be comparable in qualitative terms, that is, incapable of even being ordered in terms of 'more probable than', 'less probable than' or 'as probable as'. Probabilities are comparable if they belong to the same 'ordered series', that is, 'belong to a single set of magnitude measurable in term of a common unit'. But probabilities are not comparable if they belong to two different probability relations and one of them is not (weakly) included in the other. Keynes illustrates this point with a diagram showing different probabilistic paths, all starting with 0 and ending with 1 . A linear path accounts for the usual probabilistic representation, ranging from impossibility to certainty. But other paths between the extremes that do not lie on the straight line are also possible, representing what Keynes ([1921], p. 42) calls a 'non-numerical probability' or a 'numerically undetermined probability'. Only probabilities lying on the same path, or on paths that have points in common, are comparable, although even then he insists that 'the legitimacy of such comparison must be a matter for special inquiry in each case' (Keynes [1921], p. 40). ${ }^{5}$

It is not too difficult to see the parallels of all this with Knight's distinction between risk and uncertainty (Runde [2001]). Although Keynes did not draw an explicit distinction between risk and uncertainty in the Treatise, he too draws attention to situations that permit the determination of numerically definite probabilities (analogous to Knightian risk) and situations in which only non-numerical representations are available (analogous to Knightian uncertainty). ${ }^{6}$ However, unlike Knight, Keynes attempts to provide a mathematical structure for these non-numerical probability values. He tries to give a meaning to a numerical measure of a relation of probability through 'numerical approximation, that is to say, the relating of probabilities, which are not themselves numerical, to probabilities, which are numerical', and argues that:

5 For a brief but exhaustive presentation of Keynes's probability theory see Gillies ([2000]).

6 Keynes's later remarks on uncertainty in the General Theory support this viewpoint (Runde [1994b]). 
Many probabilities, which are incapable of numerical measurement, can be placed nevertheless between numerical limits. And by taking particular nonnumerical probabilities as standards a great number of comparisons or approximate measurements become possible (Keynes [1921], p. 176).

Keynes thus clearly points to inexact numerical comparison rather than simply to the impossibility of attributing cardinal numbers and deriving probability comparisons (Brady [1993]). ${ }^{7}$

Keynes's point is best illustrated by means of one of his own examples. In order to introduce his criticism of the frequentist viewpoint that the numerical character of probability is necessarily involved in the definition of probability as the ratio between favourable cases and the total number of cases, Keynes ([1921], pp. 23-32) provides various instances from 'the experience of practical men'. Among the concrete cases in which 'no rational basis has been discovered for numerical comparison' he refers to the practice of underwriters. In his examination of 'the willingness of Lloyd's to insure against practically any risk' Keynes rejects the conclusion that this is an argument in favour of the numerical evaluation of all probabilities. Indeed, this practice does not imply that 'underwriters are actually willing ... to name a numerical measure in every case, and to back their opinion with money' since it only means 'that many probabilities are greater or less than some numerical measure, not that they themselves are numerically definite' (Keynes [1921], p. 23).

This argument is also reminiscent of Knight. What Knight refers to as an overpriced policy is for Keynes a policy the premium for which exceeds a probable risk

\footnotetext{
${ }^{7}$ Keynes's attempt to develop what he called a 'systematic method of approximation' was later taken up by Koopman ([1940]), who provided an axiomatisation of Keynes's ideas by introducing upper and lower probabilities, thus paving the way for the modern treatment of imprecise probabilities. This literature differs from Keynes in that it does not adopt a logical interpretation of probability, but the mathematical models developing the theme of imprecise, epistemic probabilities have nevertheless drawn heavily from Keynes (Walley [1991]). More recently Basili and Zappia ([2009]) have argued that Keynes's non-numerical probabilities can be interpreted as instances of decision weights that do not meet the standard rule of probabilities and can be represented through a non-additive measure, with the degree of non-additivity representing the degree of distortion of the linear probability prior.
} 
that cannot be known. The fact that there is no rational basis for naming a premium attached to an idiosyncratic risk is made clear, in Keynes's view, by observing that different brokers usually offer different premia even on the basis of the same evidence, and that terms offered on a policy usually vary with the number of applicants. ${ }^{8}$ He points out that underwriters themselves distinguish between risks that are properly insurable, either because probabilities are known or because it is possible to make a book that covers all possibilities, and risks that cannot be dealt in the same way and 'cannot form the basis of a regular business of insurance - although an occasional gamble may be indulged with' (Keynes [1921], p. 25). On the basis of his philosophical attitude towards epistemic probabilities, Keynes thus maintains that there may be cases in which probabilities cannot be measured and estimated numerically. As a result, 'the practice of underwriters weakens rather than support the contention that all probabilities can be measured and estimated numerically' (Keynes [1921], p. 25).

\section{Insuring unique events: the subjectivist viewpoint as represented by de Finetti}

According to de Finetti, the probability of an event or proposition simply represents an individual's subjective degree of belief in that event or proposition. Objective, observer independent probabilities, simply do not exist: 'probability ... if regarded as something endowed with some kind of objective existence, is no less a misleading misconception, an illusory attempt to exteriorize or materialize our true probabilistic beliefs' (de Finetti [1975], p. x).

De Finetti ([1937], p. 111) claims that the subjective notion of probability is very close to that of 'the man in the street', that is, the one that is usually applied everyday situations. He argues that a decision-maker's personal belief in a proposition $q$ can be

\footnotetext{
${ }^{8}$ Discussing the possibility of insuring against the possible introduction of new taxes, Keynes claims that the existence of quotes offered to merchants worried by their effect on business does not imply that the relevant probabilities are known. As a matter of fact, 'that the transaction is in principle one of bookmaking is shown by the fact that, if there is a specially large demand for insurance against one of the possibilities, the rate rises; the probability has not changed, but the "book" is in danger of being upset' (Keynes [1921], p. 24).
} 
measured by finding the lowest value $P$ that she is willing to pay for a gamble that pays $S$ with probability $p$ and $T$ with probability $(1-p)$. So long as she is an expected value maximizer, she will then be indifferent between $P$ and the gamble. The real-valued probability of $q$ can then be derived from $P=p(q) S+[1-p(q)] \mathrm{T}$, so that $p(q)=(P-T$ )/(S - T). In the simple case of playing a gamble that pays $S$ with probability $p$ and nothing with probability $(1-p), P=p(q) S$ and the real valued probability is $p(q)=P / S$.

This operational definition of probability, based on qualitative comparisons of the kind just described, extends the determination of numerically definite subjective probabilities to just about any practical situation, including ones in which probabilities are being assigned to unique events (de Finetti [1937], pp. 100-1). ${ }^{9}$ It then follows that the actuarial mechanism will work in just about any possible insurance activity. While insurance and gambling surely differ in their social and economic functions, on this view, their underlying technical features are the same (de Finetti [1957 and 1967]).

To see this, consider a situation in which two individuals have to decide whether to exchange a risk. Suppose that an individual A (the insured) is faced with the possibility of a loss $L$ this coming year and that the personal probability of suffering this loss is $p$. A will be willing to buy insurance as long as the insurance premium she has to pay makes her better off in terms of expected utility. With an endowment of wealth $W$, the noninsured individual $\mathrm{A}$ has an expected utility $\mathrm{EU}^{\mathrm{A}}{ }_{\mathrm{n}-\mathrm{i}}=p \mathrm{U}(W-L)+(1-p) \mathrm{U}(W)$. By paying a premium $R^{A}$, the individual can insure herself against the loss and get $\mathrm{EU}_{\mathrm{i}}^{\mathrm{A}}=\mathrm{U}\left(W-R^{A}\right)$. The insured's reservation price is the value $R^{A *}$ that makes $\mathrm{EU}^{\mathrm{A}}{ }_{\mathrm{i}}=\mathrm{EU}^{\mathrm{A}}{ }_{\mathrm{n}-\mathrm{i}}$. If the individual is risk-neutral, then $R^{A *}=p L$. In this set-up it is straightforward to see how other hypotheses about the individual's risk attitude apply: a risk-averse individual has $R^{A *}>p L$, depending on the curvature of her utility function, with $R^{A *}-p L$ reflecting the risk premium, that is, the maximum price above the expected loss that she is willing to pay in order to remove risk by purchasing an insurance policy. Risk seeking would imply $R^{A *}<p L$.

${ }^{9}$ De Finetti ([1937]) is explicit that he wants to pursue his theoretical investigation on the qualitative notion of probability to its extreme conclusions by introducing all those axioms necessary to identify coherent numerical probabilities (see also de Finetti [1931], pp. 302-4). However, as we will detail in section 5, this does not prevent him from considering what would imply to stop before taking this last step and discuss different, qualitative options. 
The insurer's choice problem is symmetrical with that of the insured. Suppose that, on the basis of the available information, an individual B (the insurer) has the same personal degree of belief $p$ regarding the possibility that the insured will experience a loss $L$. Her problem then consists in evaluating the convenience of exchanging insurance by comparing the utility provided by her own initial capital $K$ and the utility provided by her capital in the case insurance is offered, the latter depending on future gains or losses. An insurer B with wealth $K$ earns $\mathrm{EU}^{\mathrm{B}}{ }_{\mathrm{n}-\mathrm{s}}=\mathrm{U}(K)$ by not selling insurance. By selling a single policy to $\mathrm{A}$ at a premium of $R^{B}$ she can earn $\mathrm{EU}^{\mathrm{B}}{ }_{\mathrm{s}}=p \mathrm{U}\left(K-L+R^{B}\right)+(1-p) \mathrm{U}\left(K+R^{B}\right)$. As above, the insurer's reservation price for determining whether to sell the policy will be the value $R^{B *}$ that sets $\mathrm{EU}^{\mathrm{B}}{ }_{\mathrm{s}}=\mathrm{EU}^{\mathrm{B}}{ }_{\mathrm{n}-\mathrm{s}}$. And as with the insured, the insurer's reservation price will be $R^{B *}=p L$ if she is risk-neutral, $R^{B *}>p L$ if risk-averse, and $R^{B *}<p L$ if risk seeking.

Since there are no differences in the evaluation of the probability of loss a gain from exchange in this simplified insurance market can emerge only if risk attitudes differ. $^{10}$ The more risk-averse the insurer, the higher the premium; the higher the insurer's wealth, the lower the risk premium. The problem is thus to find an insurance price that make both insurer and insured better off by exchanging insurance.

In his most comprehensive study of the insurance market, de Finetti ([1967]) maintains that the analysis of betting behaviour outlined above provides a complete explanation of the insurance mechanism: it is the difference between individuals' risk attitudes that explains the mutual convenience of exchanging an insurance contract. This explanation differs significantly from the usual explanation in the insurance literature, which starts from that the existence of a group of units that are subject to the same peril and in respect to which it is possible to talk about the frequency of an event (de Finetti [1967], p. 259). For de Finetti, in contrast, the insurer always evaluates the option of offering insurance by considering an 'isolated event', ${ }^{11}$ and an insurance portfolio is no

\footnotetext{
${ }^{10}$ Trading among individuals with identical risk attitudes can occur if their degree of risk aversion is declining with wealth (or if risk-seeking is increasing with wealth), if $K>W$.

${ }^{11}$ Subjectivists such as Borch ([1976]) take a similar line in claiming that the practice of insurers such as Lloyd's of London proves, rather than disproves, the practical irrelevance of the distinction between risk and uncertainty (Lloyd's being willing to insure against unique events such as the capture of the Loch Ness Monster).
} 
more than a set of contracts relating to a number of such isolated events. The fact that the insurer may offer insurance against many events has no effect on the profitability of each individual contract, although, all being well, total profits will increase as the number of events insured increases. The degree to which the events insured are homogeneous is irrelevant, according to de Finetti, save that attempts to increase the homogeneity of events insured will ultimately be counterproductive insofar as homogeneous events are likely to be correlated. What de Finetti calls 'compensation', the tendency for gains and losses to balance out over a large number of 'operations' with fair and uncorrelated random events, is thus more likely to work in the case of heterogeneous rather than homogeneous events (de Finetti [1967], pp. 28-9).

Moreover, when different decision-makers hold different degrees of belief regarding the occurrence or otherwise of a given event, subjectivists argue that this should encourage the exchange of insurance contracts amongst those individuals. To see why, consider two individuals who are uncertain about a set of mutually exclusive possible events. Suppose that they have identical information and utility functions. Then, given the appropriate convexity conditions, they should make identical decisions if they share the same subjective probability distribution over those events. If they do not make the same decision, absent mistakes or frictions such as differences in transactions costs, this can then only be because their subjective probabilities differ. And where so, they will be willing to enter bets with each other concerning the events in question. This phenomenon has positive consequences for the insurance market: when peoples' beliefs about possible events differ they will be more likely to exchange insurance contracts than when they have common beliefs.

\section{The 'philosophy' of practitioners}

As seen in the previous section, lying at the core of the insurance mechanism is the idea that the insurer is able to identify and quantify the risk when providing different levels of cover. If she is able to estimate the magnitude of the loss $L$ and the probability $p$ of the loss occurring, then she will be able to determine what premium to charge. If in contrast the probability of the loss is unknown, the insurer is not able to calculate the expected 
loss, set up an appropriate premium and thus to make the actuarial mechanism work. Notwithstanding the claim of subjectivist interpreters of probability, and the pervasiveness of the maximization of subjective expected utility as criterion for choice in decision theory, there remains a substantial literature claiming that insurance can cope with risk but not with uncertainty. For instance, in his analysis of social insurance, Atkinson ([1995], p. 210) observes that in dealing 'with actuarial risk, rather than what is called uncertainty in the sense of Knight [1921]', what is missing is 'the important function of social insurance in providing for contingencies which are not foreseen, or to allay fears about events which we cannot forecast'. Similarly, Barr ([2001a]) explains how the problem of unknown probabilities can arise and reviews a number of cases in which this problem seems to be relevant in explaining why private markets fail to provide a number of insurance services. The examples he covers include medical insurance concerning a specific illness (e.g. the extent of risk from exposure to 'mad cow' disease), long-term care insurance (due to increase in longevity the probability distribution of care for future cohorts of the elderly is to change over the course of contracts with long-term horizons), macroeconomic shocks, and private unemployment insurance concerning a particular individual becoming unemployed. ${ }^{12}$

Similar views emerge in studies by insurance firms themselves, analyzing the technical conditions to be satisfied for insurers to offer cover against uncertain events. Various guidelines have been proposed, and Table 1 provides a representative example of the kinds of actuarial criteria of insurability employed (Swiss Re [2005], drawing on Berliner [1982]):

12 Social insurance arises in response to private market failures (Arrow [1963]) and differs from private insurance in two important respects: (1) membership is compulsory and (2) contracts are less specific. These differences make it possible to disconnect premia from individual risks - thus departing from actuarially fair individual insurance and to cover risks that may change over time (Barr [2001a]; Atkinson [1995]) and uncertainties in the Knightian sense (Barr [2001b], p. xxiv; Feduzi and Runde [unpublished]). 
Table 1.

\begin{tabular}{c|l|l|l} 
N. & Category & Criterion & Characteristic \\
\hline 1 & & Risk/uncertainty & Measurable \\
2 & & Loss occurrences & Independent \\
3 & & Maximum loss & Manageable \\
4 & Actuarial & Average loss & Moderate \\
5 & & Loss frequency & High \\
6 & & Moral hazard, adverse selection & Not excessive \\
\hline
\end{tabular}

Source: Swiss Re (2005)

The criteria in this table most relevant for our purposes are those numbered 1,2 and $5 .{ }^{13}$ Criterion 1 states that the insurability of a risk requires that the probability of that risk must be measurable and known to the insurer. Otherwise it would not be possible to determine the insurance premium and to rely on the actuarial mechanism. Criterion 2 states that since the insurance mechanism entails losers as well as winners, probabilities have to be independent. As it is not possible to insure against so-called 'common shocks', in other words, risks in the portfolio cannot be overly correlated with one another. Finally, Criterion 5 states that in order to ensure the stability of performance, a high number of realisations is required to be able to apply the Law of Large Numbers (Swiss $\operatorname{Re}[2005]$, p. 5).

It is interesting how strongly the Knightian distinction between risk and uncertainty is reflected in the table (the same is true of the insurance literature more generally, e.g. Rejda [2001]). Criterion 1 above is normally satisfied by the adoption of a frequentist interpretation of approach to probability, on the basis that it is possible to determine an index of the relative frequency of that kind of event by looking at the proportion of times that kind of event has occurred under similar conditions over a long period. This index then represents the probability distribution attached to that event, that is, the average rate at which it is expected to occur.

${ }^{13}$ Criterion 3 states that the maximum potential loss on a particular risk should be within the bounds of what the organization as a whole can bear, and Criterion 4, that the risk profile should comprise events of moderate severity. Finally, Criterion 6 states that the problems of moral hazard and adverse selection (Rothshild and Stiglitz [1976]) associated with insuring a particular risk should be within acceptable levels. 
The Law of Large Numbers alluded to in Criterion 5 is fundamental to the insurance mechanism for three reasons. In the first place, estimating the underlying probability of the risk by the insurance company requires a sufficiently large sample. In the second place, once the probability of the risk has been estimated, it has to be applied in a large number of instances for the underlying probability to 'work itself out'. Finally, and for similar reasons, the risk has to be a frequency event: 'High frequency/low severity events such as motor accidents are ideally suited for insurance; low frequency/high severity events such as nuclear accidents are not' (Swiss Re [2005], p. 5).

The Law of Large Numbers and the related central limit theorem thus lie at the heart of the concept of pooling of losses as an insurance mechanism. The risk faced by the insurer is not just the sum of the individual risks, since it will be able to predict within narrow limits the amount of losses that will actually occur by grouping exposure units (as the average of a large number of independent and identically-distributed realisations of a random variables tends to fall close to the expected value). Adding additional exposure units to an insured pool then tends to reduce the variation of the average loss per policyholder around the expected value, although significant risk reduction through pooling can of course only be achieved when the losses are uncorrelated (Criterion 2; Harrington and Niehaus [1999]).

In summary, and returning to the Knightian distinction, insurable 'risk' requires a large group of similar but independent exposure units that are subject to the same peril. The insurer will then be able to predict the average loss based on the Law of Large Numbers and determine a premium that is consistent with covering all claims and expenses, as well as guaranteeing a profit, over the policy period. In the situations of 'uncertainty', in contrast, the probability of loss is unknown, leaving the insurer unable to calculate an appropriate premium and rely on the actuarial mechanism. The insurance market fails in this case, not because of asymmetric information, but because of the impossibility, theoretically and practically, of establishing the probability of the loss.

Practitioners confirm that the strict version of de Finetti's subjective perspective is at odds with the practice of most underwriters confronting idiosyncratic risks. Writing under the heading of 'misapplication of probability and statistics in real-life uncertainty', for example, Taylor and Shipley ([unpublished]), both of whom spent many years in the 
Lloyd's insurance market, argue that the notion of 'black swans' or 'unknown unknowns' that has gained such notoriety in the wake of the financial crisis are "part and parcel of the problem' in insurance and that in most cases, 'even the subjective workarounds of Bayesianism fail to cover up the cracks' (Taylor and Shipley [unpublished], p. 1). ${ }^{14}$ Taylor and Shipley confess that their own practice was to stand back from their model and take a view as to 'what degree of accuracy it is capable of'. It is their expertise that dictates when or when not to be confident in their models, in order to have a better chance of incorporating unexpected events into their model. Moreover, even when applying Bayesian updating to adjust for evidence there remains the problem of how to choose a prior probability distribution: 'what if we just don't have any grounds for a quantitative probabilistic model at all?'. They conclude that 'in real life we use qualitative methods for decision under high uncertainty and only use probability "numbers" as an illustration' (Taylor and Shipley [unpublished], p. 3).

Section 6 will show that this practical attitude towards probability assessments, though at odds with a strictly subjectivist viewpoint, has been made the subject of thorough examination in empirical studies under the headings of ambiguity aversion. But let us first consider de Finetti and his usually disregarded 'second thoughts' on the significance of Knight's distinction.

\section{De Finetti on uncertainty in Knight and Keynes and on insurability}

This section is mainly devoted to an exegesis of two excerpts from de Finetti's vast contribution to economics and statistics published in Italian. The first, never translated into English, comments on Knight's distinction between risk and uncertainty. The second, taken from a 1938 review article on the logical approach to probability translated into English only as late as 1985, offers de Finetti's early thoughts on Keynes's notion on non-numerical probability. We will also refer to a 1962 joint paper with Savage, often

\footnotetext{
${ }^{14}$ The terms 'black swans' and 'unknown unknowns' refer to events that are not listed in the space of possible outcomes of predictive models and then come as a complete surprise when they occur (Runde [2009]).
} 
quoted in the statistical literature but never translated into English, in which de Finetti discusses the possibility of representing non-numerical probabilities by way of intervals. We will argue that the discussion of uncertainty and its justification in the theory of probability that appears in these excerpts diverges rather sharply from the standard interpretation of de Finetti as the hardline champion of a strictly subjective approach. In short, it turns out that while he certainly took a consistently subjective view on the foundations of probability, he could be pluralistic within this general framework too. ${ }^{15}$

\subsection{De Finetti on Knight}

De Finetti considers the relevance of Knight's distinction between risk and uncertainty and its consequences for the functioning of the insurance market in his 1967 Economia delle Assicurazioni. ${ }^{16}$ He begins by pointing out that Knight's distinction is already implicit in or 'presupposed' by the frequentist approach and summarizes the distinction as follows. In situations of risk, uncertainties can be eliminated (converted into fixed costs) by the concept of 'compensation' or the possibility of transferring them to an insurer who applies the concept of 'compensation' on a large scale. In situations of uncertainty, in contrast, uncertainties are not compensable or insurable, and have to be dealt with on the basis of individual judgement (de Finetti [1967], p. 33). De Finetti points out that Knight's distinction does not depend on an individual risk actually being transferred to an insurance company, which, as something that would also be affected by institutional and contingent factors, he therefore regards as having no interesting general

${ }^{15}$ Indeed, the signs are also there in his major volume on probability, The Theory of Probability, where, drawing on de Finetti and Savage ([1962]), he discusses whether imprecise probabilities exist and admits that in certain occasions a straightforward introduction of numerical values for probabilities is not obvious and it seems preferable to start from a purely ordinal relation - i.e. a qualitative one - which either replaces the quantitative notion ... or is used as a first step towards its definition' (de Finetti [1975], p. 363). However, to the best of our knowledge this pluralistic attitude has only been noted before by Suppes and Zanotti ([1989], p. 23).

${ }^{16}$ This volume is co-authored with Filippo Emanuelli. However, de Finetti was uniquely responsible for the draft of Part I, titled L'Incertezza nell'Economia [Economics of Uncertainty]. As we quote only from Part I, we refer to it simply as de Finetti 1967. The quotations from de Finetti's 1967 volume are translated from the original Italian by the authors. 
implications. As far as theoretical issues are concerned, he reaffirms that the distinction cannot be based on the particular features of a risk that might make it theoretically uninsurable, if this consideration is independent of the fact that the private market actually insures that risk (de Finetti [1967], pp. 33-4). Indeed, de Finetti contends that every risk can be insured as long as there is someone willing to accept it, and, unsurprisingly, he argues that the practice of Lloyd's of London testifies to this (de Finetti [1967], p. 34).

De Finetti suggests that best way to test Knight's distinction is to analyse its relevance to the field of decision theory. He argues that the distinction between risk and uncertainty from the standpoint of the individual decision-maker and the distinction between insurable and uninsurable risks from the standpoint of the insurer both turn on the same question: is it always possible to apply probabilistic reasoning when making decisions whatever the situation, or can probabilistic reasoning only be applied in some cases and not in others? De Finetti's answer to this question is unequivocal: at a theoretical level, it is always possible to apply probabilistic reasoning. It is on this ground that he suggests that Knight's distinction is theoretically meaningless (de Finetti [1967], p. 35).

Since Knight's distinction is so heavily informed by the idea of the existence of objective probabilities, it is not surprising that de Finetti should reject it. Nevertheless, de Finetti ends his analysis with an observation that hints at a different interpretation of Knight's distinction: "what Knight would refer to as "risks" are cases in which one finds minor discrepancies in valuations made by different individuals, or by different insurers. This is what renders them insurable' (de Finetti [1967], p. 36). He proceeds by arguing that: 'the individual appreciation of the various risks translates (more or less explicitly) into a subjective valuation of the probability that, depending on whether the conditions are favourable, will be roughly uniform amongst the various individuals. This could even lead to the creation of an insurance market in which the valuations that are more or less accepted, constitute the foundation for the setting of premia' (de Finetti [1967], p. 37). Echoing Keynes to some extent, de Finetti argues that such uniformity of judgments is most likely to occur in games of chance or in respect of events for which statistical data is available. Outside these cases, in his view, the difference among individuals' subjective 
probabilities will depend on the particular circumstances under which they are elicited (de Finetti [1967], p. 36). De Finetti is highly doubtful that it is possible to distinguish clearly between cases in which perfect uniformity among judgments exists and cases in which it does not (or between cases in which some objective conditions which lead to perfect uniformity among judgments exist and cases in which they do not). And if these divisions are always a matter of degree, according to de Finetti, Knight then erred in trying to draw too sharp a line between risk and uncertainty, and thereby leaving the impression that the distinction is clear-cut and fundamental rather than fuzzy and secondary. It is for this reason that de Finetti ([1967], p. 37) ultimately refuses to adopt the Knighting terminology.

De Finetti nevertheless hints at an interesting interpretation of the Knightian distinction that has recently been revived within the subjectivist approach: that a situation of uncertainty may be interpreted as one in which peoples' opinions about the probability of a given event sensibly differ. To this extent, then, there is a sense in which de Finetti holds a notion of Knightian uncertainty after all. Further, even though he regards people as always attaching sharp numerical probabilities to events, de Finetti admits that insurance markets may nevertheless fail. That is to say, and this should probably not be surprising in view of his more than 30-year association as a practitioner at Assicurazioni Generali, he is fully aware that the adoption of subjective probabilities does not guarantee complete markets as postulated by the standard economic model of risk exchange.

To see what is involved here, consider the following example. Imagine that there are a number of individuals want to buy insurance against the occurrence of a given loss $L$ and that the losses are uncorrelated across individuals. Suppose that due to the absence of reliable historical data the insurer has only a rough idea of the probability $p$ that the loss $L$ will occur, and therefore decides to ask various experts to evaluate $p$. Suppose further that some of these experts estimate that the value of $p$ is $p^{*}$ while the others estimate that the value of $p$ is $p_{*}$, where $p^{*}>p_{*}$. The question then is whether the insurer should take into account the Knightian uncertainty thus reflected, in the process of deciding the premium. 
Subjectivist might argue that the answer to this question should be no, on the grounds that Knightian uncertainty is irrelevant because the insurer will in any event always use point-value subjective probabilities to calculate the expected value of the loss. ${ }^{17}$ We reject this view, however, because the insurer will still have to find a way to aggregate the experts' opinions. And it turns out that Knightian uncertainty does have bite here. Suppose that the insurer decides that she has to take her experts seriously and, as she sees no reason to favour one estimate over the other, decides to give them equal weight by basing the insurance premium on the mean of the two, that is, $p=\left(p^{*}+p_{*}\right) / 2$. In this case the expected loss would be $\mathrm{E}(L)=p L$. The problem, however, is that the insurer knows that the average loss could well differ from $\mathrm{E}(L)=p L$, and likely be closer to either $\mathrm{E}(L)^{*}=p^{*} L$ or to $\mathrm{E}(L)_{*}=p_{*} L$. The insurer will thus perceive a large variance in the distribution of average loss around the expected value $\mathrm{E}(L)=p L$.

This last phenomenon is known as 'exposures with parameter uncertainty' in the literature on insurance and risk management, where parameter uncertainty increases the variance of the distribution of average losses around the insurer's estimate of the expected loss per policy and has the same effect as high correlation in losses (Harrington and Niehaus [1999], p. 166). Since the insurer's estimate may be wrong, any error in the estimate of expected loss will apply to all policyholders. There will then be correlation in the insurer's estimation errors across policyholders, and the insurer will have an incentive to overload the insurance premium in order to reduce the risk of insolvency.

\subsection{De Finetti on Keynes}

In his 1938 Italian review of the works of 'Cambridge probability theorists', Keynes's Treatise on Probability and Jeffreys's Scientific Discovery, de Finetti praises the renewed interest in the epistemic perspective of scholars engaged in foundational studies. The differences between the objective perspective implicit in the logic of probability endorsed by Keynes and his own subjective interpretation are pointed out (de Finetti [1938], pp.

${ }^{17}$ This would be the position of authorities like Savage who, while recognising that 'there seem to be probability relations about which we feel relatively "sure" as compared with others' (Savage [1954], p. 57), ultimately takes the view that '[s]ome people see the vagueness phenomenon as an objection; I see it as a truth, sometimes unpleasant but not curable by a new theory' (Savage [1962], p. 163). 
83-4). ${ }^{18}$ But de Finetti supports what he sees as a revival of an epistemic approach to probability blurred by the empiricist perspective of frequency probability, and praises Keynes's idea of interpreting probability theory as the logic of thinking determining the 'degree of uncertainty [of propositions] at a given time when there is not enough information to judge them true or false'. ${ }^{19}$

This favourable attitude towards Keynes is not limited to the link between his probability theory and the epistemic approach, and has a counterpart in a specific comment de Finetti makes on the question of measurable probabilities. De Finetti recalls that, when discussing how the theory of probability translates into probability calculus, Keynes admits neither the postulate that each probability is a number between 0 and 1 , nor that two probabilities are always comparable one with the other. From de Finetti's perspective, 'Keynes's position is certainly not suited to the development of a mathematical probability theory and is also hardly in keeping with the intuitive idea of probability' (de Finetti [1938], p. 88). But he also concedes that Keynes's position deserves consideration with respect to one specific aspect: "without denying that for each individual the probabilities for two events must be comparable, it may be that, based on certain assumptions shared by all, certain inequalities already have a determinate sense which is common to everyone's opinion, whereas others vary from individual to individual'. As an example de Finetti ([1938], p. 88) adds: 'one can assume, for example, the equal probability of certain events which are in a certain sense symmetrical, e.g. of a slightly oblong die, one may say that two square faces are equally probable and also that the four oblong faces are equally probable but more probable than the square sides. In that case, we must admit that this probability will fall between $1 / 6$ and $1 / 4$ (and $4 a+2 b=$ 1 with $0<\mathrm{b}<\mathrm{a}$ ), but it is not determined which values between $1 / 6$ and $1 / 4$ will obtain and, based on the only assumption made, we may expect that each individual will

${ }^{18}$ On the significance of de Finetti's critique of logical probability see Galavotti ([1989]) and Gillies ([2000]).

19 As noted by Gillies and Ietto-Gillies ([1987]), in this article de Finetti stressed the similarities between his view and that of Keynes. The difference with Ramsey's comments on the Treatise is striking. Ramsey ([1926]), the other main early proponent of the subjectivist approach, was harshly critical of the logical approach. On Ramsey's critique and Keynes's reaction to it, see Runde ([1994a]). 
evaluate that probability differently'. De Finetti concludes that, though at odds with his own subjective viewpoint of probability 'it would not be at all irrational to interpret this in agreement with Keynes as an absence of comparability'.

This concession suggests some sympathy with Keynes's insistence on the possibility of non-numerical probabilities and is of relevance for our reconstruction of de Finetti's nuanced understanding of uncertainty. Indeed, following our assessment of Keynes in Section 2 above, non-numerical probabilities may be related to the problem of interval probabilities and multiple priors, a point de Finetti himself was aware of and discussed in a joint work with Savage, published in Italian in 1962, and never translated into English. This paper, devoted to a discussion of 'how to choose initial probabilities' from a subjectivist perspective, considers the question of whether 'inexactly determined' and 'fuzzy' initial opinions can be expressed through an exact probability value as a secondary issue, but examines it in detail. Here it is conceded that 'it is often practically impossible to anyone to state that ... the probability which he can attribute to a certain event has a precise value' (de Finetti and Savage [1962], p. 95), and that imprecision can constitute an 'actual epistemic state' of the individual facing uncertainty whose nature is 'difficult to be made precise in a convincing manner' (de Finetti and Savage [1962], p. $134) .^{20}$

The 1962 paper discusses Smith ([1961]), who followed Ramsey and de Finetti himself in measuring beliefs by means of betting quotients, but showed that a person consistently rejecting to bet on either an event or its complement can be attributed an interval of initial probabilities. ${ }^{21}$ De Finetti and Savage admit that Smith provided a precise criterion to determine two initial probability values $p_{*}$ and $p^{*}$, where $p^{*}>$ $p_{\text {* }}$, and take the 'fact' that there may be a 'non-betting zone' for granted. Among the

\footnotetext{
${ }^{20}$ These and the following quotations from de Finetti and Savage ([1962]) are translated from the original Italian by the authors

${ }^{21}$ Smith ([1961]) presented his work as a generalisation of the subjective approach to admit imprecision. He introduced the fundamental principles of avoiding sure loss and coherence in the context of interval probabilities of Koopman and Good, and interpreted upper and lower probabilities as personal betting quotes. Smith provided also an extension of interval probabilities to statistical inference and decision-making, showing that coherent lower probabilities can be seen as lower envelopes of precise probability measures. For an analysis of Smith's role in the development of imprecise probability see Walley ([1991]).
} 
reasons justifying the reluctance of actual individuals to bet on certain events, it is mentioned the case of an insurance firm that specialises in certain insurance fields and reject to insure others. Also it is envisaged that an individual may reject to bet on fields in which she feels herself incompetent (de Finetti and Savage [1962], pp. 136-9). As for the normative content of Smith's interval probabilities, Smith's approach is criticised, but considered of help in those cases in which one has 'partial knowledge' of a preference and the probability of an event can be said to be indeterminate. Among these cases two are singled out as more relevant: first, the case of a number of decision-makers who are to make a collective decision, and, second, the case of a single individual who experiments 'kind of personality dissociation' (de Finetti and Savage [1962], p. 142). The first case in which Smith's approach is admitted to be sound even on normative grounds largely repeats de Finetti's justification of Knight's notion of uncertainty. The second case coincides with de Finetti's understanding of Keynes non-numerical probabilities. ${ }^{22}$

It is apparent then that de Finetti and Savage's analysis of interval probabilities has clear links with the two excerpts discussing Knight and Keynes, and that it can be related to the modern treatment of imprecise beliefs in decision-making. On the multiple prior approach (Levi [1974]; Gärdenfors and Sahlin [1988]) decision situations are described as 'risky' when the decision-maker's beliefs can be represented by a single probability distribution, and 'uncertain' when they cannot. The second case is then accommodated within the standard expected utility framework by replacing the customary unique probability distribution with a set of probability distributions. The idea is that the multiplicity of the subjective distributions represents the decision-maker's ignorance about the true probability distribution.

Following Bewley ([1986]) let us analyse the consequences of the multiple prior approach by examining again the decision-maker's behaviour in betting situations. We have seen that if the decision-maker is willing to exchange an amount $P$ for a gamble that

\footnotetext{
${ }^{22}$ As an attempt at clarification an example is offered, concerning the unknown area of a given scalene triangle: under certain constraints to its sides the triangle can assume different areas, but this does not mean that the triangle has an indeterminate area, it means only that it can assume different values and there is not enough information to identify it (de Finetti and Savage [1962], p. 142). This example replicates the one used to justify Keynes's argument in the 1938 review.
} 
pays $S$ if $q$ is true and nothing if $q$ is false, then $p(q)=P / S$. Further, since the subjective approach implies that the decision-maker is always willing to offer or accept bets at odds that represent her degrees of belief (Kyburg [1978]), then she should be willing to accept an amount $P$ in exchange for a gamble that involves a loss of $S$ if $q$ is true and nothing otherwise, such that $P / S=-P /-S=p(q)$. But now suppose that the decision-maker has only a vague idea of the value $P$ and, in particular, is not prepared to commit to any more than $P$ lying somewhere in the interval $\left[P_{*}, P^{*}\right]$, with $P^{*}>P_{*}$. Under these circumstances, she will be willing to offer any amount $P<P_{*}$ in exchange for $S$ if $q$ is true and nothing otherwise, and to accept any amount $P>P^{*}$ in exchange for $S$ if $q$ is true and nothing otherwise. Crucially, however, she will not be prepared to offer or accept bets if $P$ is included between $P_{*}$ and $P^{*}$ (Fig. 1).

\section{Figure 1}

\begin{tabular}{c|cc}
\hline Offer & & Accept \\
\hline$P_{*}$ & $P^{*}$
\end{tabular}

In this case, the decision-maker's beliefs are represented by the interval $\left[p_{*}(q), p^{*}(q)\right]$, where $p_{*}(q)=P_{*} / S$ and $p^{*}(q)=-P^{*} /-S$.

The preceding analysis has interesting consequences for the completeness assumption of mainstream decision theory. The completeness assumption states that for every pair of options $x$ and $y$, the decision-maker either prefers $x$ to $y$, prefers $y$ to $x$, or is indifferent between $x$ and $y$. According to expected utility theory, a decision-maker with complete preferences is always able to compare any two lotteries and decide or declare indifference between them. Where the decision-maker's beliefs are represented by a multiplicity of probability distributions, however, each lottery will be associated with a corresponding set of expected utilities. One lottery will then be strictly preferred to another if and only if each of the expected utilities associated with it exceeds the highest expected utility associated the other lottery (Rigotti and Shannon [2005]). The difficulty that arises, however, is that there may well be cases in which the expected utility intervals associated with the two lotteries overlap, and where it is then not possible to say that one 
unambiguously dominates the other. In these cases the decision-maker's preferences will be incomplete: there will be pairs of lotteries in respect of which she neither prefers one lottery to another nor is indifferent between them. This idea makes it possible to characterise aversion to uncertainty: where lotteries cannot be ranked uniformly, decision-makers may well respond by refraining from making a choice and taking an action.

The consequences of the multiple prior approach for the functioning of the insurance market follow directly. Suppose that two individuals have to decide whether to exchange a bet that pays $S$ in the event of $E$ occurring and nothing otherwise, and where there is no objective probability to go on ${ }^{23}$ Suppose further that individual 1 regards the

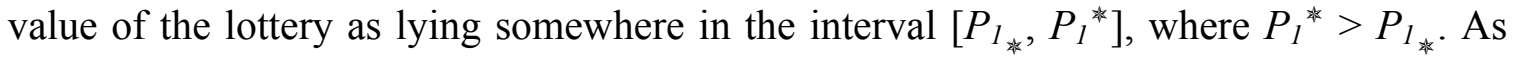
demonstrated above, under these circumstances, she will be willing to bet on $E$ for any amount $P<P_{I_{*}}$, accept bets against $E$ for any amount $P>P_{1}{ }^{*}$; and will shun bets for any amount $P$ in the interval $\left[P_{I_{*}}, P_{I}{ }^{*}\right]$. Her degrees of belief are thus represented by the interval between $p_{I_{*}}=P_{I_{*}} / S$ and $p_{1}{ }^{*}=-P_{I}{ }^{*} /-S$. Suppose that individual 2 is also not prepared to commit to a single set of point-valued probabilities and, on the same basis as just outlined, that her own beliefs are represented by the interval between $p_{2_{\text {水 }}}=P_{2_{\text {水 }}} / S$ and $p_{2}{ }^{*}=-P_{2}^{*} /-S$.

Whether or not it is possible to come up with a bet that is attractive to both individuals depends on the values they attach to $P_{*}$ and $P^{*}$, and thus to their interval priors. They will exchange a bet if and only if the minimum probability attached to $E$ by one is greater than the maximum probability attached to the same event by the other (Bewley [1986], [1989]). This situation is shown in Fig. 2. below, where both individuals will be better off if they can exchange at a value of $P$ somewhere in the interval between $P_{2}^{*}$ and $P_{1_{*}}$.

${ }^{23}$ To keep things simple we ignore the possibility of risk aversion. 
Figure 2

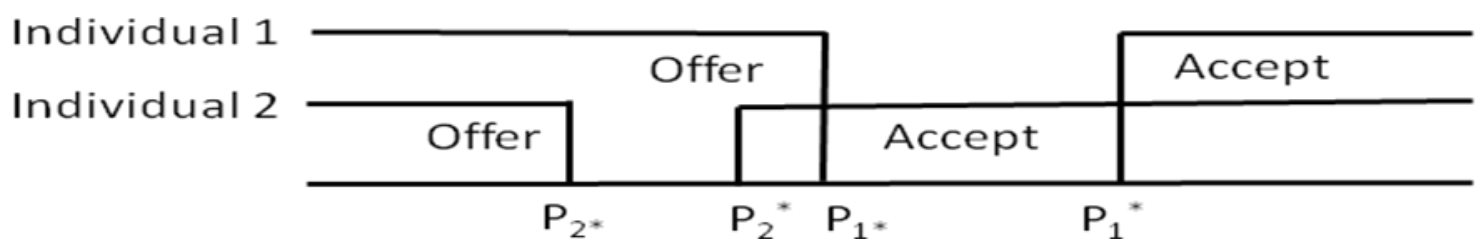

When there is no place in which one individual's offer range overlaps with the other's accept range, no bet will be exchanged (Fig. 3).

\section{Figure 3}

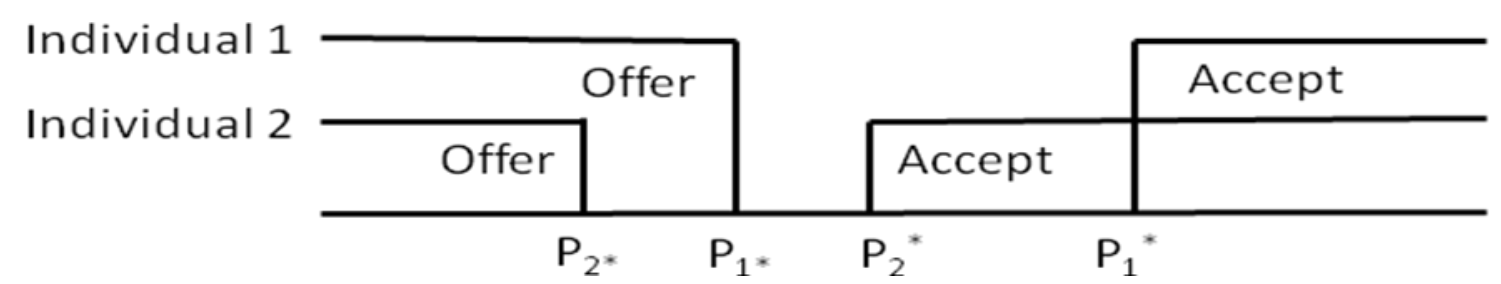

The multiple prior approach thus captures the situation in which two rational decisionmakers might have divergent views on the probability of some event and yet refuse to exchange a bet on that event. Since taking out insurance is formally equivalent to taking a bet on the subjective view, this kind of situation is analogous to the absence of insurance markets for uncertain events.

\section{Empirical evidence on insurance under ambiguity}

As the material summarised above suggests, de Finetti's discussion of the key elements underpinning Knight's and Keynes's analyses of uncertainty makes a theoretical case for uncertainty within the subjectivist approach and provides solid theoretical ground for understanding the failure of insurance market to cover highly uncertain events. But how good is all this as a description of actual insurance industry practice?

As it turns out, the last twenty years or so have seen several empirical studies of how actuaries, underwriters and reinsurers set premia for insuring uncertain events, and 
which show that all three of these groups exhibit a large degree of uncertainty aversion (Hogarth and Kunreuther [1985], [1989], [1995]; Kunreuther and Hogarth [1992]; Kunreuther et al. [1993]; Kunreuther et al. [1995]; Cabantous [2007]). These studies have in turn precipitated a number of efforts to explain the failure of the insurance market to cover highly uncertain contingencies by reviving the distinction between risk and uncertainty under the heading of ambiguity. ${ }^{24} \mathrm{~A}$ good example here is Cabantous ([2007]) who, following Smithson ([1999]), surveyed a group of 78 professional actuaries, all members of the French Institute of Actuaries. Each of her subjects received a questionnaire containing scenarios involving pollution and an earthquake, with three informational conditions provided in each case. For instance, in the pollution case, the insurers were provided with the following information in each of three situations:

1) Risk, where environmental studies have established with precision that the probability of pollution damage to the firm is $p=0.002$;

2) Ambiguous and consensual, where experts agree that the probability of pollution damage to the firm lies within the interval [0.001, 0.003] and that the mean probability of the risk is $p=0.002$;

3) Ambiguous and conflicting, where one group of experts estimates that the probability is $p=0.001$ and the other group estimates that the probability is $p=$ 0.003 .

${ }^{24}$ As in most of the recent developments in decision theory following Ellsberg ([1961]), the notion of ambiguity is used to identify situations in which the individuals' information concerning the likelihood of events is perceived to be scanty or unreliable. Einhorn and Hogarth ([1986], p. 227) define ambiguity as 'uncertainty about uncertainties'. They claim that when assessing uncertainty in the real world the analogy with gambling devices can be misleading, as 'beliefs about uncertain events are typically loosely held and ill defined'. On this view, ambiguity can be high when 'evidence is unreliable and conflicting' (Einhorn and Hogarth [1986], p. 230). The notion of ambiguity used in the works we refer to in this section mostly overlaps with that of uncertainty discussed in the previous sections. However, this literature refers neither to de Finetti, nor to the notions of Knightian uncertainty and Keynesian uncertainty discussed in this paper. 
The interesting thing about this scheme from the point of view of the present paper, is that the 'ambiguous and conflicting' and 'ambiguous and consensual' situations correspond exactly to the two theoretical possibilities raised by de Finetti in his responses to the conceptions of uncertainty arising in Knight and Keynes respectively.

Cabantous asked the actuaries to specify the premium they would charge to provide insurance in each of these three situations, and where they could effectively reject requests for insurance by setting premia so high as to discourage buyers completely. Her principal finding, that uncertainty aversion was pervasive amongst the actuaries tested (i.e. that the premia charged in the second and third situations were higher than in the first in which the point probability was known), provides support for de Finetti's theoretical arguments for uncertainty within the subjectivist approach having practical implications for the functioning of insurance markets. ${ }^{25}$ In particular, de Finetti's reflections on Knight's and Keynes's analyses of uncertainty go a long way to providing theoretical grounds for insurers failing to offer insurance for highly uncertain contingencies, or attempting to raise premia beyond levels that most people can afford.

\section{Conclusion}

The economics of insurance provides a clear case of interaction between philosophy and economics. Authors interested in the philosophical foundations of probability such as Knight and Keynes have devoted great attention to the possibility of applying

${ }^{25}$ Cabantous also found that the actuaries were more averse to uncertainty in the 'ambiguous and conflicting' situation than they were in the 'ambiguous and consensual' situation. Possible explanations for this phenomenon include Shanteau's ([2001]) 'experts should converge' hypothesis and Smithson's ([1999]) 'conflict aversion' hypothesis. It is worth pointing out in this connection that, as they are in a position of having to sell their choices and their behaviour generally to clients, insurance company operatives have an incentive to be seen as arriving at similar probability judgements. Further, as they are members of organisations that have responsibilities towards their superior executives and shareholders, they have an incentive to present their probability evaluations as objective insofar as these must be seen as those of the organization as a whole. We are grateful to a referee for these points. 
probabilistic reasoning to the insuring of single events. We have argued that despite the philosophical differences in the foundations of their respective theories of probabilities, both Knight and Keynes suggest that insurance markets cannot provide insurance against truly 'uncertain' events since in this case probabilities either do not exist or cannot be measured, and maintain that insurers like Lloyd's of London being prepared to insure against unique events is hardly evidence that sharp numerical probabilities can be assigned to all events.

Knight's and Keynes's philosophical positions on this subject have largely fallen off the radar as a consequence of the dominance of the SEU model associated with Savage ([1954]), which incorporates the 'orthodox' subjective conception of numerically definite probabilities stemming from the work of de Finetti ([1937]) himself. However, on the basis of some overlooked excerpts from de Finetti's vast contribution to economics and statistics published in Italian, we have shown that his position on the treatment of uncertainty does not always conform to his usual image as a champion of a strictly subjective approach. To be sure, de Finetti's quest for a consistent theory of subjective probability is probably still best represented by his choice to pursue the stringent perspective of point probability estimates when considering his overall contribution to the philosophy of probability. But he certainly did consider variants of subjective probability such as that proposed by Smith ([1961]) as a viable alternative, and we have shown that he actually made a theoretical case for uncertainty within the subjectivist approach by reinterpreting the Knight/Keynes distinction between risk and uncertainty within a pure subjectivist framework. Furthermore, despite the failure of the economic literature to recognize these reinterpretations, there is increasing empirical evidence to the effect that both versions can help explain the difficulties of the insurance market in covering highly uncertain events.

\section{Acknowledgements}

Comments on an earlier draft of the paper by Marcello Basili, Aldo Montesano, and two anonymous referees are gratefully acknowledged. 


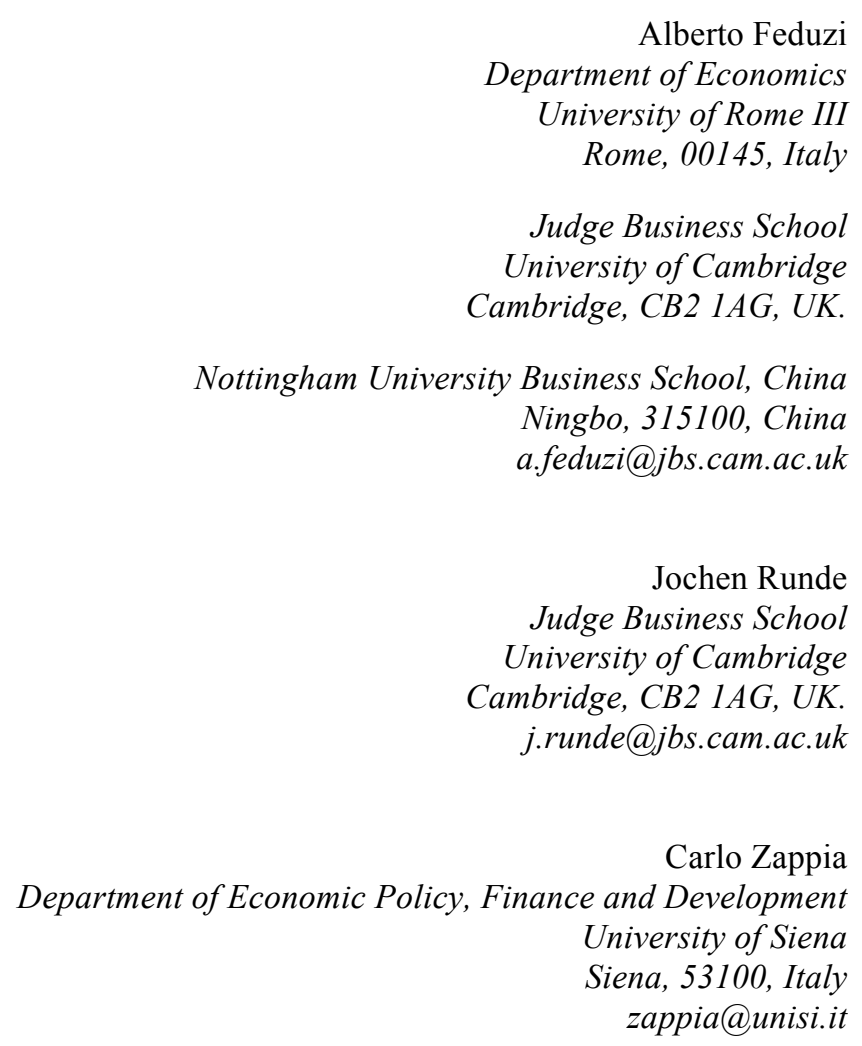

\section{References}

Arrow, K. J. [1963]: 'Uncertainty and the Welfare Economics of Medical Care', American Economic Review, 53, pp. 941-73.

Atkinson, A. B. [1995]: Incomes and the Welfare State: Essays on Britain and Europe, Cambridge: Cambridge University Press.

Barr, N. [2001a]: The Welfare State as Piggy Bank. Information, Risk, Uncertainty, and the Role of the State, Oxford: Oxford University Press.

Barr, N. [2001b]: Economic Theory and the Welfare State, London: Edward Elgar.

Basili, M. and Zappia, C. [2009]: 'Keynes's "non-numerical" probabilities and nonadditive measures', Journal of Economic Psychology, 30, pp. 419-30.

Bewley, T. F. [1986]: 'Knightian Decision Theory: Part I', Cowles Foundation Discussion Paper, n. 807, New Haven. Reprinted in Decision in Economics and Finance, 2002, 25, pp. 79-110. 
Bewley, T. F. [1989]: 'Market innovation and entrepreneurship: A Knightian View', New Haven: Cowles Foundation Discussion Paper, n. 905.

Berliner, B. [1982]: Limits of insurability of risks, Englewood Cliffs: Prentice-Hall.

Billot, A. [1992]: 'From fuzzy set theory to non-additive probabilities: how have economists reacted?', Fuzzy Sets and Systems, 49, pp. 75-90.

Borch, K. [1976]: 'The Monster in Loch Ness', The Journal of Risk and Insurance, 43, pp. 521-5.

Brady, M. E. [1993]: 'J. M. Keynes's theoretical approach to decision making under condition of risk and uncertainty', The British Journal for the Philosophy of Science, 44, pp. 357-76.

Cabantous, L. [2007]: 'Ambiguity Aversion in the Field of Insurance: Insurers' Attitude to Imprecise and Conflicting Probability Estimates', Theory and Decision, 62, pp. 219-40.

de Finetti, B. [1931]: 'Sul significato soggettivo della probabilità', Fundamenta Matematicae, 17, pp. 298-329.

de Finetti, B. [1937]: 'Foresight: Its Logical Laws, Its Subjective Sources', in H. E. Kyburg and H. E. Smokler (eds), Studies in Subjective Probability, [1964], New York: John Wiley \& Sons, pp. 93-158.

de Finetti, B. [1938]: 'Probabilisti di Cambridge', Supplemento Statistico ai Nuovi Problemi di Politica, Storia ed Economia, 4, pp. 21-37. English translation in Decisions in Economics and Finance, 1985, 8, pp. 79-91.

de Finetti, B. [1957]: Lezioni di Matematica Attuariale, Roma: Edizioni "Ricerche". de Finetti, B. [1967]: L'Incertezza nell'Economia. Part One of B. de Finetti and F. Emanuelli, Economia delle Assicurazioni, Torino: Unione Tipografico-Editrice Torinese.

de Finetti, B. [1975]: Theory of Probability, Vol. 2, New York: John Wiley and Sons.

de Finetti, B. and Savage, L. J. [1962]: 'Sul modo di scegliere le probabilità iniziali', Biblioteca del Metron, Serie C, pp. 81-154.

Ellsberg, D. [1961]: 'Risk, Ambiguity and the Savage Axioms', Quarterly Journal of Economics, 75, pp. 643-69. 
Einhorn, H. J. and Hogarth, R. M. [1986]: 'Decision making under ambiguity', Journal of Business, 59, pp. 225-50.

Feduzi, A. and Runde, J. [unpublished]: 'The uncertain foundations of the welfare state', University of Cambridge and University of Rome III.

Galavotti, M. C. [1989]: 'Anti-realism in the philosophy of probability: Bruno de Finetti's subjectivism', Erkenntnis, 31, pp. 239-61.

Gärdenfors, P. and N.E. Sahlin [1988]: 'Unreliable Probabilities, Risk Taking and Decision Making', in P. Gärdenfors and N. E. Sahlin (eds), Decision, Probability and Utility, Cambridge: Cambridge University Press, pp. 313-34.

Gillies, D. A. [2000]: Philosophical Theories of Probability, London: Routledge.

Gillies, D. A. and Ietto-Gillies, G. [1987]: 'Probability and economics in the works of Bruno de Finetti', Economia Internazionale, 40, pp.192-207.

Gollier, C. [2005]: 'Some aspects of the economics of catastrophe risk insurance', in Catastrophic Risks and Insurance, Paris: OECD Publishing, 13-30.

Gollier, C. [2007]: 'The determinants of the insurance demand by firm', Tolouse: IDEI Working Papers.

Harrington, S. E. and Niehaus, G. R. [1999]: Risk management and insurance, Boston: McGraw-Hill.

Hogarth, R. M. and Kunreuther, H. [1985]: 'Ambiguity and insurance decisions', The American Economic Review: Papers and Proceedings, 75, pp. 386-90.

Hogarth, R. M. and Kunreuther, H. [1989]: 'Risk, Ambiguity, and Insurance', Journal of Risk and Uncertainty, 2, pp. 5-35.

Hogarth, R. M. and Kunreuther, H. [1995]: 'Decision Making under Ignorance: Arguing with Yourself', Journal of Risk and Uncertainty, 10, pp. 15-36.

Jeleva, M. and Villeneuve, B. [2004]: 'Insurance contracts with imprecise probabilities and adverse selection', Economic Theory, 23, pp. 777-94.

Keynes, J. M. [1921]: A Treatise on Probability, The Collected Writings of John Maynard Keynes, vol. VIII, London: Macmillan, 1973.

Knight, F. [1921]: Risk, Uncertainty and Profit, University of Chicago Press: Chicago.

Koopman, B. O. [1940]: 'The axioms and algebra of intuitive probability', Annals of Mathematics, 41, pp. 269-92. 
Kunreuther, H. and Hogarth, R. M. [1992]: 'How Does Ambiguity Affect Insurance Decisions?', in G. Dionne (ed), Contributions to Insurance Economics, Boston: Kluwer Academic Publishers, pp. 307-24.

Kunreuther, H., Hogarth, R. M. and Meszaros, J. [1993]: 'Insurer Ambiguity and Market Failure', Journal of Risk and Uncertainty, 7, pp. 71-87.

Kunreuther, H., Hogarth, R. M., Meszaros, J. and Spranca, M. [1995]: 'Ambiguity and Underwriter decision processes', Journal of Economic Behaviour and Organization, 26, pp. 337-52.

Kyburg, H. E. [1978]: 'Subjective Probability: Criticisms, Reflections, and Problems', Journal of Philosophical Logic, 7, pp. 157-180.

Kyburg, H. E. [2002]: 'Don't take unnecessary chances!', Synthese, 132, pp. 9-26.

Levi, I. [1974]: 'On Indeterminate Probabilities', Journal of Philosophy, 71, pp. 391-418. Ramsey, F. P. [1926]: 'Truth and Probability', in P. Gärdenfors and N.-E. Sahlin (eds), Decision, Probability and Utility: Selected Readings, 1988, Cambridge: Cambridge University Press, pp. 19-47.

Rejda, G. E. [2001]: Principles of Risk Management and Insurance, Boston: Addison Wesley Longman.

Rigotti, L. and Shannon, C. [2005]: 'Uncertainty and Risk in Financial Markets', Econometrica, 73, pp. 203-43.

Rothshild, M. and Stiglitz, J. [1976]: 'Equilibrium in insurance markets: An essay on the economics of imperfect information', Quarterly Journal of Economics, 90, pp. $629-49$.

Runde, J. [1994a]: 'Keynes after Ramsey: in defence of A Treatise on Probability', Studies in History and Philosophy of Science, 25, pp. 97-121.

Runde, J. [1994b]: 'Keynesian uncertainty and liquidity preference', Cambridge Journal of Economics, 18, pp. 129-44.

Runde, J. [1998]: 'Clarifying Frank Knight's discussion of the meaning of risk and uncertainty', Cambridge Journal of Economics, 22, pp. 539-46.

Runde, J. [2001]: 'Chances and choices: notes on probability and belief in economic theory', in U. Maki (ed), The economic world view: studies in the ontology of economics, Cambridge: Cambridge University Press, pp. 132-53. 
Runde, J. [2009]: 'Dissecting the Black Swan', Critical Review, 21, pp. 491-505.

Savage, L. J. [1954]: The Foundations of Statistics, New York: Wiley.

Savage, L. J. [1962]: 'Bayesian statistics', in R. E. Machol and P. Gray (eds), Recent Developments in Decision and Information Processes, New York: MacMillan.

Shanteau, J. [2001]: 'What does it mean when expert disagree?', in E. Salas and G. Klein (eds), Linking Expertise and Naturalistic Decision Making, Mahwah: Lawrence Erlbaum Associates.

Smith, C. A. B. [1961]: 'Consistency in statistical inference and decision', Journal of the Royal Statistical Society, Series B, 23, pp. 1-37.

Smithson, M. [1999]: 'Conflict aversion: preference for ambiguity vs conflict in sources and evidence', Organizational Behavior and Human Decision Processes, 79, pp. 179-98.

Suppes, P. and Zanotti, M. [1989]: 'Conditions on lower and upper probabilities to imply probabilities', Erkenntnis, 31, pp. 323-45.

Swiss Re [2005]: 'Innovating to insure the uninsurable', Sigma, 4, pp. 1-36.

Taylor, P. and Shipley, D. [unpublished]: 'Probably wrong - Misapplications of probability and statistics in real life uncertainty', University of Oxford.

Walley, P. [1991]: Statistical Reasoning with Imprecise Probabilities, London: Chapman and Hall. 